\title{
The orthodontist's views regarding academic education in cleft lip and palate as well as craniofacial deformities in South Africa
}

SADJ May 2021, Vol. 76 No. 4 p181 - p186

E Ghabrial', K-W Bütow ${ }^{2}$

\section{ABSTRACT}

\section{Background}

Orthodontists are essential members of a craniofacial team (American Cleft Palate-Craniofacial Association Team Standards Committee). ${ }^{1}$ Because cleft lip/palate (CLP) and craniofacial deformities (CFD) vary in severity and facial growth patterns, treatment is complex and lengthy and requires collaboration among different disciplines. Consequently, orthodontists need specialised training in this field to reach the treatment goals of good facial growth, aesthetically acceptable appearance, and dental occlusion. Therefore, it becomes increasingly important to provide adequate training for orthodontists, so they can not only provide efficient treatment but can also undertake a leadership role in the field.

\section{Objectives}

To obtain information regarding:

- the CLP and CFD academic education of orthodontists the professional services that orthodontists offer to CLP and CFD patients

- the educational and training needs of orthodontists in this field

\section{Method}

A 54-item online survey to collect quantitative data was conducted by means of an interview, using a randomised sample of orthodontists attending the annual scientific conference of the South African Society of Orthodontics.

\section{Author affiliations:}

1. Emad Ghabrial: $B c h D, M c h D$ (Orthod.), $P h D$, Discipline of Dentistry, School of Health Sciences, University of KwaZulu-Natal, KwaZulu-Natal, South Africa.

ORCID Number: 0000-0002-7213-9760

2. Kurt-W Bütow: MChD (MFOSurg), DrMedDent PhD DSc (Odont) FCMFOS, FIBCSOMS, Discipline of Dentistry, School of Health Sciences, University of KwaZulu-Natal. Professor and Head of Department Emeritus, and former Head of the Cleft Lip and Palate Clinic of the University of Pretoria, Pretoria, South Africa. ORCID Number: 0000-0002-7213-9760

The research paper is a part of fulfilment $\mathrm{PhD}$ degree at Discipline of Dentistry, School of Health Sciences, University of KwaZulu-Natal. Corresponding author: Emad Ghabrial

Discipline of Dentistry, School of Health Sciences, University of

KwaZulu-Natal, KwaZulu-Natal, South Africa.

Email: emad.ghabrial@up.ac.za

Author contributions:

1. Emad Ghabrial: Principal author - $70 \%$

2. Kurt-W Bütow: Second author - $30 \%$
Results

The questionnaire was completed by 53 orthodontists, $54.6 \%$ of whom had more than 10 years of professional experience. Of the respondents, $84.8 \%$ experienced some clinical exposure in this field during their postgraduate education.

Treatment for CLP and CFD patients was offered by $92 \%$ of the professionals, but only $21.7 \%$ had high confidence in their expertise in treating CLP/CFD patients. Of the respondents, $88 \%$ agreed there was a need to improve CLP and CFD education, and the majority recommended fellowship training and certified courses. The rest suggested continuing-education workshops.

\section{Conclusion}

Most of the orthodontists provided treatment for both CLP and CFD patients despite some of them lacking confidence in treating such cases. The majority agreed that there is a strong need to establish an educational strategy to meet the needs of orthodontists who treat CLP and CFD patients. The respondents suggested that programmes such as fellowship training, degree couses, certified courses, and continuing education workshops could be used.

\section{Keywords}

Orthodontics, cleft palate, cleft lip, multidisciplinary, education, professional development, survey.

\section{INTRODUCTION}

A multidisciplinary team approach for managing patients with cleft lip/palate (CLP) and craniofacial deformities (CFD) has been advocated by practitioners. ${ }^{2-4}$ The orthodontist has become an essential member of multidisciplinary teams, according to the American Cleft Palate-Craniofacial Association team guideline. ${ }^{1}$ Orthodontist is actively involved in the life of a patientborn with a CLP/CFD from birth to adulthood. This may include infant presurgical orthopaedics, early mixed dentition treatment, dentofacial orthodontics, and preparation for alveolar bone graft procedures and pre-prosthetic and surgical orthodontics. ${ }^{4}$ Consequently, orthodontic treatment is considered a core service in the management of CLP 
and CFD. ${ }^{5-6}$ The orthodontist role within the craniofacial team has been widened to include the holistic approach of diagnosis and treatment planning. Consequently, they are involved in record taking of the overall treatment and the outcomes. Therefore, the orthodontists provide essential data for participation in inter-center comparisons of treatment outcomes and implement a quality control system for CLP/CFD care..$^{7-9}$

For many years, researchers and practitioners have understood the need to enhance academic education and clinical experience in CLP and CFD to provide quality management and improve access to care for all patients and their families. ${ }^{10-12}$ One of the earliest attempts to evaluate education in the CLP field was made by Lass et al. (1973) ${ }^{13}$, who assessed students' exposure to CLP treatment by means of a questionnaire.

Their main finding was that there was a lack of clinical exposure and basic theoretical education. Even though children with deformities' health and well-being depend on the clinical expertise of those who serve them. ${ }^{14}$ Berkowitz ${ }^{15}$ and McCarthy ${ }^{16}$ recommend further education for orthodontists in CLP/CFD to enable them to provide adequate care.

The quality of care of all patients is inevitably influenced by the adequacy of the treatment he or she receives. ${ }^{17}$ Cleft lip/palate and craniofacial deformities patient treatment relies on the teaching and exposure that the student received at university and the knowledge gained throughout the practitioner's career. ${ }^{18}$ It is necessary to obtain information about orthodontists' education in the CLP/CFD field and determine what training/instruction those learners receiving. Therefore, continuous evaluation by practitioners of the education and training of orthodontists is necessary to obtain their views on improving educational resources. ${ }^{19}$

\section{METHOD}

Ethical permission was obtained from the Humanities and Social Sciences Research Ethics Committee of the University of KwaZulu-Natal. The research survey was completed by South African orthodontists using an online questionnaire to investigate their education and their services to CLP/CFD patients. The researcher developed a quantitative research tool consists of a 54-item structured questionnaire. Qualtrics Research Suite survey software was used to capture and analyse the data. The questionnaire was designed to collect quantitative data using a Likert-type scale. Two students' volunteers perform data gathering. Respondents were selected through a Systematic Random Sampling when coming out of the lecture room during the South African Orthodontic Society's annual scientific meeting. Consent to participate was obtained from each respondent before completing the questionnaire.

\section{Questionnaire design}

The questionnaire consisted of four sections: the first determined whether the participants were accepted for inclusion in the study as a South African qualified orthodontist. The second section collected the level of knowledge and experience of and services provided by the participants. In the third section, their educational needs and preferences regarding further education were determined. The last section collected demographic data, including title, gender, age, degree(s), and location by region.

\section{Selection of participants}

Two students interviewed a random sample of orthodontists at an annual scientific conference of the South African Society of Orthodontics. Regarding sample size, the author used the literature information. ${ }^{20-21}$ The sample size was reviewed upward, from the literature information to $46.4 \%$ of the Medpages ${ }^{22-23}$ register of practising orthodontists, to account for a possible sampling error of $15 \%$.

\section{Distribution}

The researcher received permission from the South African Society of Orthodontics to randomly interview orthoontists, using an online questionnaire, during an annual scientific congress. The questionnaire was developed and piloted by a conveniently selected sample of practitioners. It was subsequently revised based on their responses to ensure data was captured appropriately.

\section{Data analysis}

The data was captured using Excel 2013. The data was later converted into Stata 15s (string) format. The analysis undertaken was descriptive summary statistics presenting frequencies and associated percentages. No other analytical tools were used because no hypothesis was being tested.

\section{RESULTS}

The questionnaire was completed by 53 orthodontists, representing most of South Africa's provinces (Fig. 1). Of these practitioners, $54.6 \%$ had more than 10 years of professional experience (Fig. 2). In the basic knowledge questions about CLP, 52\% of the respondents were uncertain of the correct answers. When asked about their educational experience, $84.8 \%$ stated that they had clinical exposure during their postgraduate education, and $72.9 \%$ had participated in multidisciplinary meetings in the course of their degree. A total of $89.8 \%$ gained their knowledge from textbooks and received their information by means of lectures (didactic input) (Fig. 3).

Even though $92 \%$ of the respondents offered treatment to both CLP and CFD patients, only $30.4 \%$ of them participated in multidisciplinary teams. Regarding the services provided according to patients' age group, 35.7\% offered orthodontic treatment for 11-18-year-old patients, and $28.2 \%$ provided services to $7-10$-year-olds. Only $10.2 \%$ offered services to infants and children between the ages of four and six. When the respondents were asked about the facility where CLP patients were consulted and treated, the following locations emerged: private practice (38.3\%), academic hospitals (33.3\%), and government hospitals (19.7\%). Only three of the respondents offered their services at charity organisations. 


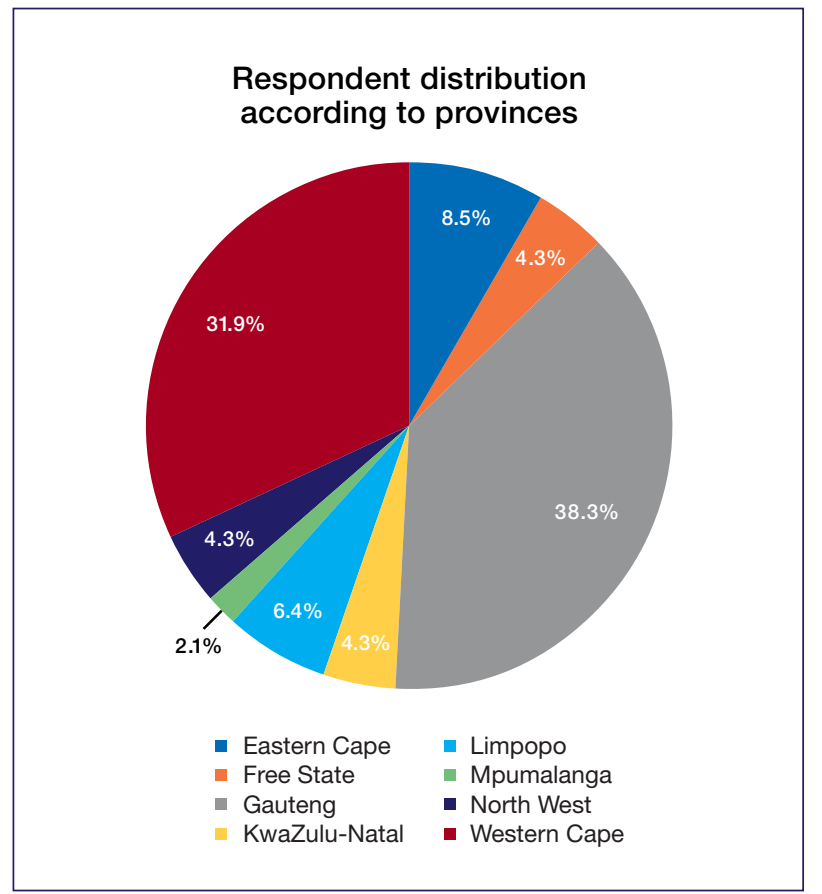

Figure 1. Respondent distribution according to provinces.

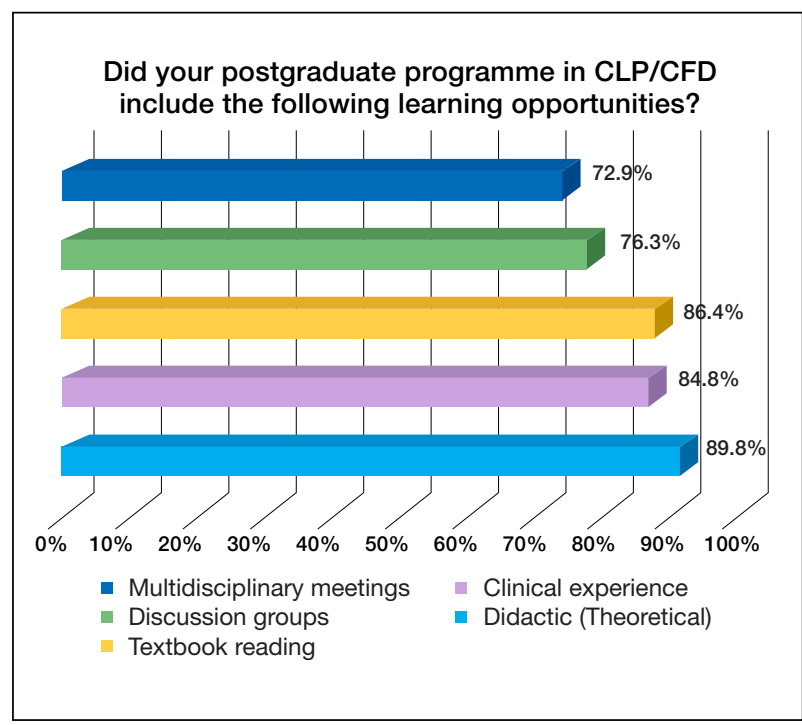

Figure 3. Did your postgraduate programme in CLP/CFD include the following learning opportunities?.

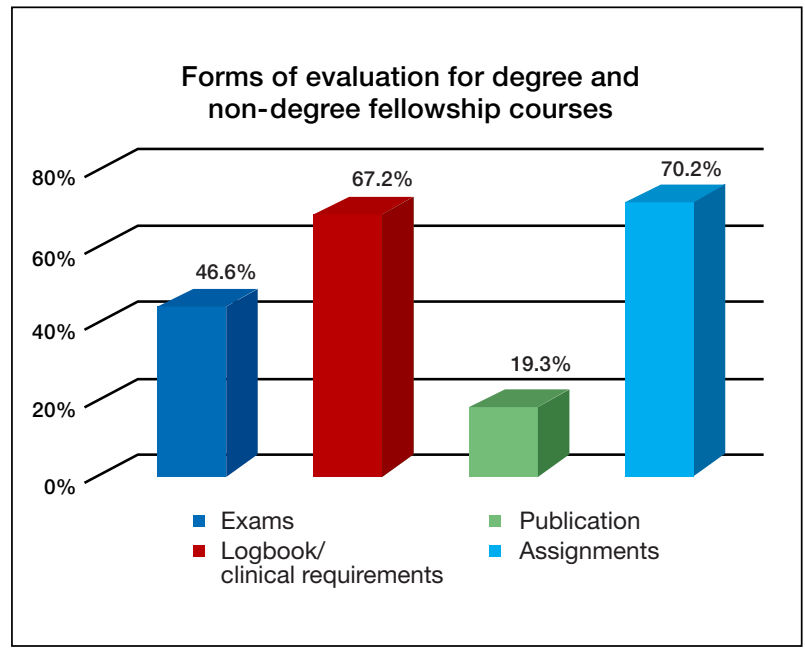

Figure 5. Forms of evaluation for degree and non-degree fellowship courses.

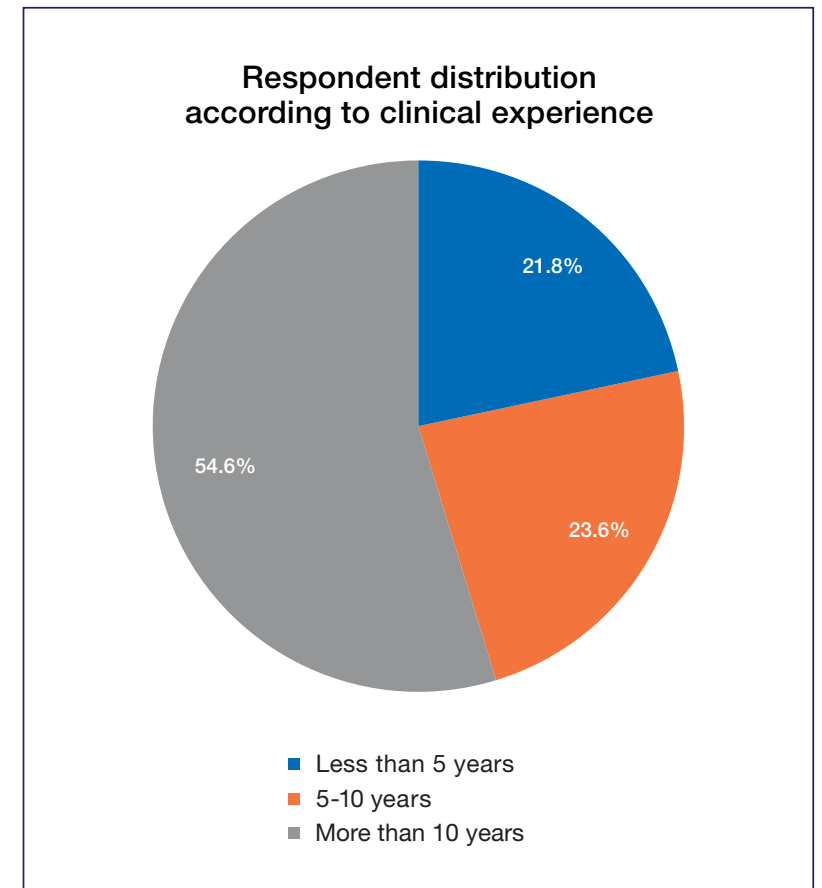

Figure 2. Respondent distribution according to clinical experience

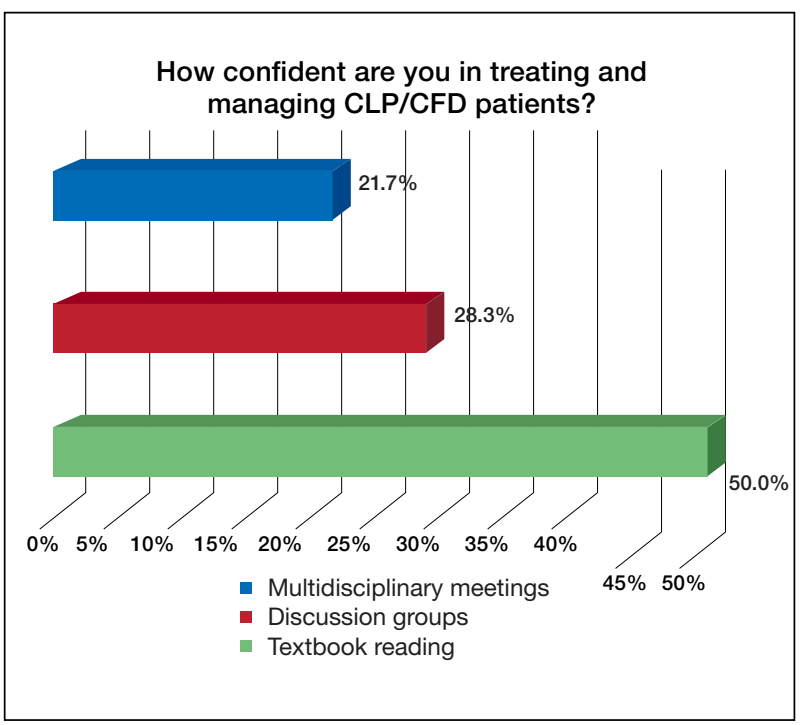

Figure 4. How confident are you in treating and managing CLP/CFD patients?.

When the service provider respondents were asked to indicate a scale of 11-0, they were confident in treating CLP and CFD patients. Fifty percent admitted having low confidence, $28.3 \%$ were moderately confident, and only $21.7 \%$ stated that they were highly confident in treating CLP/CFD patients (Fig. 4).

They also acknowledged that the CLP/CFD treatment is challenging and requires special training. They indicated that special training is needed due to the multidisciplinary approach (37\%), the lengthy treatment (30.4\%), and patients' socio-economic situation (28.5\%). A few respondents cited the emotional issues in the openended questions, and CLP/CFD poor oral hygiene added to the treatment challenges.

Almost all the respondents agreed on the need to improve the academic education offered to CLP/CFD ortho- 
dontic care providers, and $91.3 \%$ recommended dedicated educational training programmes in that field. Of the respondents, $50 \%$ would like to further their knowledge, $27.5 \%$ were unsure, and the rest said they needed no additional training.

When participants were asked about the preferred method of education,

- the majority $(41 \%)$ recommended fellowship training.

- 30.8\% recommended short courses.

- $26.9 \%$ recommended degree courses; and

- only $1.3 \%$ considered that participation in a multidisciplinary clinic is sufficient to gain the required knowledge (Table 1).

\begin{tabular}{l|c}
\hline Table 1. Type of course recommended (percentages) & \\
\hline Fellowship training & 41.0 \\
\hline Degree course & 26.9 \\
\hline CPD courses & 30.8 \\
\hline Voluntary participation in multidisciplinary team & 1.3
\end{tabular}

Participants identified interest, passion, and the prospect of joining a multidisciplinary team as the most significant reasons for enrolment in CLP- and CFD-dedicated courses. When asked about the goals and objectives of the educational programme(s), the participants suggested that the focus should be on diagnosis, treatment planning, clinical skills, and a multidisciplinary approach.

Of the respondents, $67 \%$ recommended keeping a logbook of the cases treated in clinical training, as well as preparing assignments. A total of $46.5 \%$ suggested participating in examinations, and $19.3 \%$ proposed a published article as effective evaluation methods for certificate courses (Fig. 5).

\section{DISCUSSION}

This study is important because there has never been researching into the extent of orthodontists' training in CLP/CFD care in South Africa. Academic education and training of practitioners can predict access to adequate care for patients with CLP/CFD.

A series of surveys of orthodontics education programmes have been undertaken, but these were administered to students..$^{24-25}$ In the current study, attention was given to information obtained from orthodontists with varying years of experience, from different locations and places of employment, to overcome postgraduate student limitations in clinical experience.

In line with Nobel et al., ${ }^{26}$ most of the participants of this study had formal training in treating patients with CLP and CFD. Despite this, respondents expressed the need for further training and clinical exposure to better prepare to provide services to such patients.

Several previous academic education' surveys ${ }^{27}$ used email or postal questionnaires. Few studies used incentives to improve the response rate. ${ }^{28}$ This study achieved a $46.4 \%$ response rate using interviews with attendees at their annual scientific congress, ${ }^{29}$ which is a statistically valid amount. ${ }^{30}$
This study found that participants had adequate CLP/ CFD theoretical education and some clinical exposure during their postgraduate programme that prepared them to offer treatment to CLP/CFD patients. This contrasts with Pannbacker et al., ${ }^{31}$ who found that legally qualified practitioners to provide treatment know very little about these deformities.

This investigation revealed a desire on the part of orthodontists for developmental and dedicated educational programmes in managing patients born with CLP and CFD, in line with the findings of Noble et al. ${ }^{26}$ Of the respondents, $41 \%$ recommended a fellowship (matching the current trend in different parts of the world). ${ }^{16}$

The majority of the respondents suggested that the training emphasises discussions and clinical contact, with evaluation through formal examinations and a logbook recording clinical hours. This could be linked to a clinical fellowship programme in line with the standards set by the American Dental Association for accredited fellowship programmes. ${ }^{32}$

As stated by Schoenbrunner et al., ${ }^{33}$ comprehensive CLP/CFD training can only be offered by a multidisciplinary affiliated centre, where a high volume of craniofacial procedures is performed by specialists in the field. Furthermore, centres that offer craniofacial orthodontics and surgery fellowships demonstrate the strongest relationship of success among CLP/CFD centres. ${ }^{34}$

Regarding candidate selection, the respondents suggested that criteria should include a professional degree(s), the number of years qualified, and possibly even an admission examination. However, the respondents did not consider other requirements, such as research experience and publications, to be significant in candidate selection.

The findings contrast with the results of Grewal et al., ${ }^{35}$ that candidates published in a scientific journal are a good indicator of those who would be effective to be a candidate for further education. Otherwise, the respondents recommended research input as a part of the course objective and the evaluation of all candidates.

\section{CONCLUSION}

As the orthodontist's field expands, there is less training in uncommon problems like CLP/CFD during their postgraduate education. Orthodontists may be confronted with the need to provide services that they are not highly confident in performing. Therefore, orthodontists need to have advanced training to reach proficiency in providing CLP/CFD care.

This study shows a demand from the participants for advanced education and training in the CLP/CFD fields, and a desire for academic institutions to adopt educational strategies and provide subspecialty courses like the traditional postgraduate diploma or in an online degree format. Such training can provide orthodontists with the knowledge and confidence to provide correct care to CLP/CFD patients and play a fundamental role in multidisciplinary teams by investigating treatment outcomes and implementing quality control measures. 


\section{Limitations}

This survey represents those orthodontists' opinions attending an annual scientific conference in September 2017 who were randomly selected and willing to be interviewed. Those orthodontists who did not participate in the study may have different views.

The study could be benefited from testing the hypothesis "information and training done in the postgraduate programme is adequate to provide treatment service to CLP and CFD patients."

\section{Acknowledgments}

The authors would like to thank the Gerald Gavron Research Fund of the South African Society of Orthodontics for financial support, SAS Olorunju PhD, the Biostatistics Unit of the South African Medical Research Council for providing statistical support, and Professor FA de Wet (Professor Emeritus and previous Deputy Chairperson of the School of Dentistry) for proofreading the manuscript.

\section{Appendix 1}

The dataset supporting the conclusions of this article is not currently available, as it is part of the researcher's PhD thesis. The questionnaire used to collect the data is available from the corresponding author on request.

\section{Declaration}

This article is based on a study done by the researcher in partial fulfillment of his $\mathrm{PhD}$ thesis.

\section{Authors' contribution}

Prof. K-W Bütow is the author's PhD supervisor; the researcher conceptualised and designed the PhD study. The researcher collected and analysed all the data. Both authors contributed to writing and editing the manuscript and approved the final version.

\section{Funding}

The PhD project was funded by the SA Society of Orthodontics Gerald Gavron Fund. The funding sources were not involved in the design of the study, data collection analysis, interpretation of results, or writing the manuscript.

\section{Conflicts of interest}

The authors declare no conflict of interest.

\section{References}

1. Strauss RP. Cleft palate and craniofacial teams in the United States and Canada: A national survey of team organization and standards of care. The American Cleft Palate-Craniofacial Association (ACPA) Team Standards Committee. Cleft Palate Craniofac J. 1998; 35(6): 473-80.

2. Bütow KW. Treatment of cleft lip and palate. Part V: The clinic and the multidisciplinary approach to cleft lip and palate cases. J Dent Assoc S Afr. 1984; 39(8): 543, 5.

3. Marks M. A teamwork approach to cleft palate rehabilitation in South Africa. S Afr J Commun Disord. 1960; 7(2): 8-10.

4. Santiago PE, Grayson BH. Role of the craniofacial orthodontist on the craniofacial and cleft lip and palate team. Semin Orthod. 2009; 15(4): 225-43.

5. Auslander M, Brown A, Dalston R, Elmendorf E, Elster B, Jones $\mathrm{M}$, et al. Parameters for evaluation and treatment of patients with cleft lip/palate or other cranofacial anomalies. Cleft Palate Craniofac J. 1993; 30 (Suppl.).

6. Long Jr RE, Semb G, Shaw WC. State of the art - orthodontic treatment of the patient with complete clefts of lip, alveolus, and palate: Lessons of the past 60 years. Cleft Palate Craniofac J. 2000; 37(6): 533.

7. Prahl-Andersen B. Controversies in the management of craniofacial malformations. Semin Orthod. 2005; 11(2): 67-75.

8. Vig KW, Mercado AM. Overview of orthodontic care for children with cleft lip and palate, 1915-2015. Am J Orthod Dentofacial Orthop. 2015; 148(4): 543-56.

9. Pruzansky S. The role of the orthodontist in a cleft palate team. Plast Reconstr Surg. 1954; 14(1): 10-29.

10. Dabed CC, Cauvi DL. Survey of dentists' experience with cleft palate children in Chile. Cleft Palate Craniofac J. 1998; 35(5): 430-5.

11. Gadbury-Amyot CC, Simmer-Beck M, McCunniff M, Williams KB. Using a multifaceted approach including community-based service-learning to enrich formal ethics instruction in a dental school setting. J Dent Educ. 2006; 70(6): 652-61.

12. Kobes HR, Pruzansky S. The cleft palate team - a historical review. Am J Public Health Nations Health. 1960; 50(2): 200-5.

13. Lass NJ, Gasperini RM, Overberger JE, Connolly ME. The exposure of medical and dental students to the disorder of cleft palate. Cleft Palate J. 1973; 10(56): 306-11.

14. Parameters for evaluation and treatment of patients with cleft lip/palate or other craniofacial differences. Cleft Palate Craniofac J. 2017; 55(1): 137-56.

15. Berkowitz S. Teaching orthodontic residents and clinicians about cleft palate treatment. Am J Orthod Dentofacial Orthop. 2010; 138(2): 127.

16. McCarthy JG. Development of craniofacial orthodontics as a subspecialty at New York University Medical Center. Semin Orthod. 2009; 15(4): 221-4.

17. Berkowitz $S$. The need to establish an online cleft palate teaching program for orthodontic residents and practicing orthodontists. Am J Orthod Dentofacial Orthop. 2010; 137(5): 577.

18. McDonald J, Adamidis J, Eaton K, Seeholzer H, SieminskaPiekarczyk B. A survey of postgraduate (specialist) orthodontic education in 23 European countries. Br J Orthod. 2000; 27(1): 83-98.

19. Kern DE, Thomas PA, Hughes MT. Curriculum development for medical education: A six-step approach. $2^{\text {nd }}$ ed. Baltimore, MD: Johns Hopkins University Press. 2009.

20. Modi N, Ross E. The current practices, training and concerns of a group of hospital-based speech therapists working in the area of dysphagia. The South African Journal of communication disorders. 2000; 47: 3-14.

21. Thandeka M, Penelope F, Robin J. Are South African speech-language therapists adequately equipped to assess English Additional Language (EAL) speakers who are from an indigenous linguistic and cultural background? A profile and exploration of the current situation. South African Journal of Communication Disorders. 2016; 63(1): e1-5. 
22. Medpages, South Africa: [updated 7 Sep 2016; cited 28 July 2017]. Available from: https://www.medpages.info/sf/index. php?page=services.

23. Manana PN, Kuonza L, Musekiwa A, Koornhof $H$, Nanoo A, Ismail N. Feasibility of using postal and web-based surveys to estimate the prevalence of tuberculosis among health care workers in South Africa. PloS one. 2018; 13(5): e0197022.

24. Adeyemi TA. Cleft lip and palate care in Nigeria: Current status of orthodontic residents' training in the management of children with cleft lip and palate. J Craniofac Surg. 2015; 26(4): 1106-8.

25. Keim RG, Sinclair PM. Orthodontic graduate education survey. Am J Orthod Dentofacial Orthop. 2002; 121(1): 2-8.

26. Noble J, Karaiskos N, Wiltshire WA. Future provision of orthodontic care for patients with craniofacial anomalies and cleft lip and palate. World J Orthod. 2010; 11(3): 269-72.

27. Pannbacker M, Lass NJ, Scheuerle JF, English PJ. Survey of services and practices of cleft palate-craniofacial teams. Cleft Palate Craniofac J. 1992; 29(2): 164-7.

28. Bedwinek AP, Kummer AW, Rice GB, Grames LM. Current training and continuing education needs of preschool and school-based speech-language pathologists regarding children with cleft lip/palate. Lang Speech Hear Serv Sch. 2010; 41(4): 405-15.

29. Flanigan TS, McFarlane E, Cook S, editors. Conducting survey research among physicians and other medical professionals: A review of current literature. Proceedings of the Survey Research Methods Section, American Statistical Association. 15 May, 2008; 1: 4136-47. Available from: https://pdfs.semanticscholar.org/097a/47c2221285aa0529300a1add9015844 edc35.pdf.
30. Asch DA, Jedrziewski MK, Christakis NA. Response rates to mail surveys published in medical journals. J Clin Epidemiol. 1997; 50(10): 1129-36.

31. Pannbacker M, Lass NJ, Starr P. Information and experience with cleft palate: Students, parents, professionals. Cleft Palate J. 1979; 16(2): 198-205.

32. Accreditation Standards for Clinical Fellowship Training Programs in Craniofacial and Special Care Orthodontics. Commission on Dental Accreditation. American Dental Association 2013. Available from: https://www.ada.org/ /media/CODA Files/ortho_fellowship.pdf?la=en.

33. Schoenbrunner AR, Dalle Ore CL, Lance S, Mclntyre J, Jones M, Gosman A. Effect of surgeon volume and craniofacial fellowship training on cleft palate complication rates. Ann Plast Surg. 2017; 78 (5 Suppl 4): S229-S32.

34. Plana NM, Massie JP, Stern MJ, Alperovich M, Runyan CM, Staffenberg DA, et al. The drivers of academic success in cleft and craniofacial centers: A 10-year analysis of over 2000 publications. Plast Reconstr Surg. 2017; 139(2): 450-6.

35. Grewal NS, Spoon DB, Kawamoto HK, Jones NF, Da Lio AL, Crisera $\mathrm{C}$, et al. Predictive factors in identifying subspecialty fellowship applicants who will have academic practices. Plast Reconstr Surg. 2008; 122(4): 1264-71.

\section{Do the CPD questionnaire on page 226}

The Continuous Professional Development (CPD) section provides for twenty general questions and five ethics questions. The section provides members with a valuable source of CPD points whilst also achieving the objective of CPD, to assure continuing education. The importance of continuing professional development should not be underestimated, it is a career-long obligation for practicing professionals.

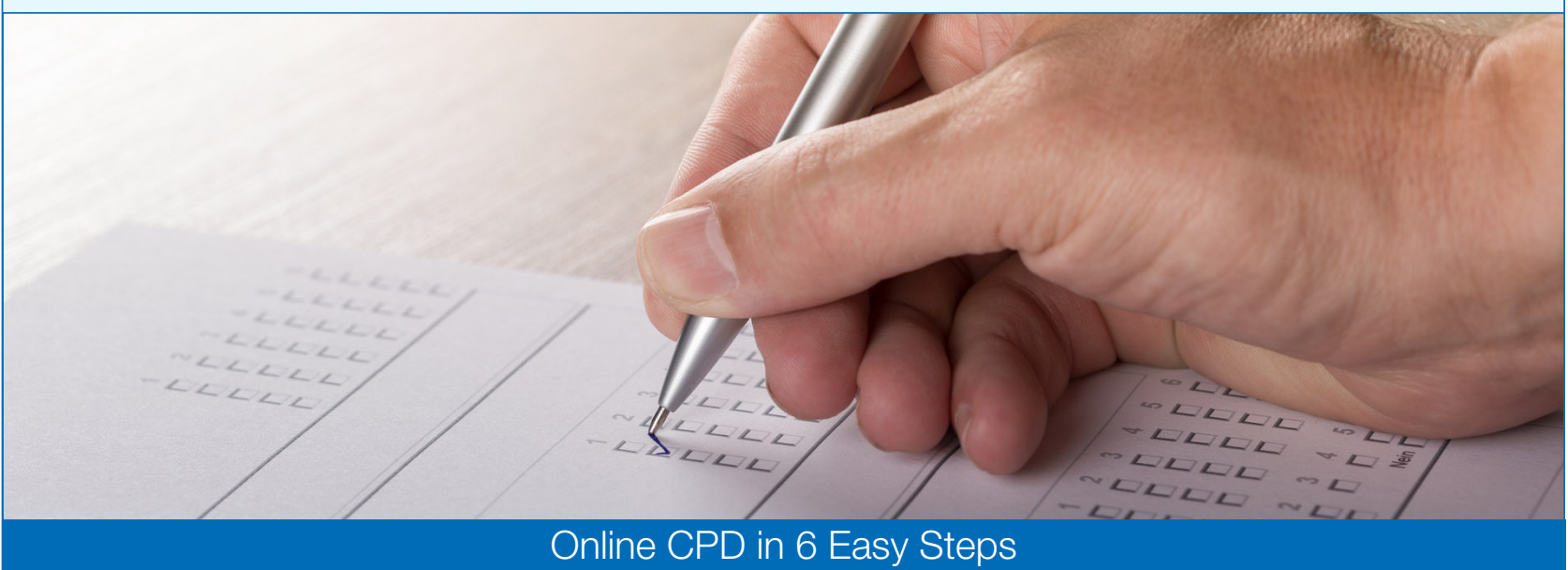

1. Go to the SADA website www.sada.co.za.

2. Log into the 'member only' section with your unique SADA username and password.

3. Select the CPD navigation tab.

4. Select the questionnaire that you wish to complete.

5. Enter your multiple choice answers. Please note that you have two attempts to obtain at least $70 \%$.

6. View and print your CPD certificate. 